\title{
Effects of dopaminergic modulation on electrophysiological brain response to affective stimuli
}

\author{
Ingmar H. A. Franken • Ilse Nijs • Lolke Pepplinkhuizen
}

Received: 14 June 2007 / Accepted: 3 September 2007 / Published online: 22 September 2007

(C) Springer-Verlag 2007

\begin{abstract}
Introduction Several theoretical accounts of the role of dopamine suggest that dopamine has an influence on the processing of affective stimuli. There is some indirect evidence for this from studies showing an association between the treatment with dopaminergic agents and selfreported affect.

Materials and methods We addressed this issue directly by examining the electrophysiological correlates of affective picture processing during a single-dose treatment with a dopamine D2 agonist (bromocriptine), a dopamine D2 antagonist (haloperidol), and a placebo. We compared early and late event-related brain potentials (ERPs) that have been associated with affective processing in the three medication treatment conditions in a randomized double-blind crossover design amongst healthy males. In each treatment condition, subjects attentively watched neutral, pleasant, and unpleasant pictures while ERPs were recorded.

Results Results indicate that neither bromocriptine nor haloperidol has a selective effect on electrophysiological indices of affective processing. In concordance with this, no effects of dopaminergic modulation on self-reported posi-
\end{abstract}

\footnotetext{
I. H. A. Franken · I. Nijs

Erasmus Affective Neuroscience Lab, Institute of Psychology, Erasmus University Rotterdam,

Rotterdam, The Netherlands

L. Pepplinkhuizen

Department of Neuroscience, Erasmus Medical Center, Rotterdam, The Netherlands

I. H. A. Franken $(\varangle)$

Institute of Psychology, Erasmus University Rotterdam,

Woudestein J5-43, P.O. Box 1738, 3000 DR Rotterdam,

The Netherlands

e-mail: franken@fsw.eur.nl
}

tive or negative affect was observed. In contrast, bromocriptine decreased overall processing of all stimulus categories regardless of their affective content.

Discussion The results indicate that dopaminergic D2 receptors do not seem to play a crucial role in the selective processing of affective visual stimuli.

Keywords Dopamine · ERP · Haloperidol · Bromocriptine · Affective processing

\section{Introduction}

Dopaminergic neurotransmission has been suggested to be involved in several functions of the brain that are associated with reward, such as the experience of rewarding feelings (Wise and Bozarth 1985), reward-related reversal learning (Mitul et al. 2001), motivational aspects of reward (Robinson and Berridge 1993), and reward processing (Day and Carelli 2007). In addition, dopamine neurons mediate reward signals in appetitive learning of visual stimuli (Schultz 1997). Recently, Robbins and Everitt (2007) stated that "the role of enhanced DA activity is to increase responsivity to cues paired with reinforcement". In addition to these functions, there are suggestions that dopamine is involved in the regulation of affect (Saeedi et al. 2006). Most studies addressing the role of dopamine in affect-regulation have been carried out among animals. Few studies address the role of dopamine in affect among humans. Studies among Parkinson's disease patients, whose mesencephalic dopamine activity is decreased, show that dopamine is able to modulate emotional responding (Wieser et al. 2006). In addition, it has been demonstrated that dopamine is also involved in the perceptual processing of fearful stimuli in Parkinson disease patients (Tessitore et al. 2002). No studies 
are known which address whether dopamine is able to modulate the processing of affective stimuli in normal subjects. However, there are some indirect suggestions pointing towards a role of dopamine in affective processing. Takahashi et al. (2005) showed among healthy volunteers watching unpleasant pictures that the dopamine D2 receptor antagonist sultopride decreased responses in the limbic areas (amygdala, hippocampus, anterior cingulate), which are associated with affective processing. In contrast, they found that sultopride produced greater activations in the cortical areas (frontal, temporal, and parietal), and no effect of sultopride on self-reported affect was found, suggesting a complex role of dopamine in affective processing.

With regard to psychopathology, what several theoretical accounts of psychopathological behavior have in common is that they state that dopamine may have a function in signaling relevant or salient information (Franken 2003; Kapur 2003; Robinson and Berridge 1993) and suggest that dopamine is involved in the processing of information having motivational relevance. In concordance with this notion, Franken et al. (2004) showed that the attention-capturing properties of heroin-related stimuli in heroin-dependent patients were decreased as result of treatment with the dopamine antagonist haloperidol. Indirect evidence that dopamine is involved in the processing of affective information comes from a study of Taylor et al. (2005) among schizophrenics. They found that structures with extensive dopaminergic innervations, such as the ventral striatum, show blunted responses to emotional salience in schizophrenics.

In addition, several theories suggest that dopamine is involved in the experience of self-reported positive affect (Ashby et al. 1999; Burgdorf and Panksepp 2006). In concordance with these notions, several studies examining the effects of dopamine-antagonists, in particular D2 antagonists such as haloperidol, report a blunting of the self-reported affective response (e.g., Mizrahi et al. 2007). In contrast, dopamine agonists result in self-reported enhanced mood (Saeedi et al. 2006; Willner et al. 2005).

In the present study, we use event-related potentials (ERPs) to investigate the processing of affective stimuli, in particular reward-associated stimuli, in humans. ERPs measured during the perception of pictures are known to vary with their affective contents (Cacioppo et al. 1994; Cuthbert et al. 2000; Keil et al. 2001; Schupp et al. 2000). Affective pictures, both pleasant and unpleasant, elicit larger late positive potentials (LPP; starting 300-400 ms after picture onset until picture offset) than neutral pictures. LPPs capture controlled processes and are generated by a diffuse network including anterior areas such as the orbitofrontal cortex (Rule et al. 2002; Vuilleumier 2005) and higher order visual areas such as parietal and occipitotemporal regions (Keil et al. 2002). In addition to these late effects, the viewing of affective pictures results in reduced
ERP amplitudes in the early time window $(150-300)$ as compared to neutral stimuli (Codispoti et al. 2007; Schupp et al. 2006). This early ERP effect is sometimes referred to as the early posterior negativity (EPN; Schupp et al. 2003b). The EPN, which is associated with the perceptual encoding of emotional material, may reflect the call for resources in the capacity-limited second stage of processing (Codispoti et al. 2007; Schupp et al. 2006) and is generated in the visual occipito-temporal regions (Schupp et al. 2006).

In passive viewing contexts such as in the present study, the EPN and LPP modulation by affective stimuli are similar in respect to the fact that they are both pronounced for high arousing pleasant and unpleasant stimuli (Schupp et al. 2006). However, it seems that the LPP, in contrast to the EPN, is enlarged when allocating top-down attentional resources to emotion, suggesting that the EPN is relatively insensitive to voluntarily attentional processes. Previous studies show that similar designs that study the electrophysiological activation to affective pictures are able to measure the modulation of affective processing by psychopharmacological agents (Franken et al. 2007; Kemp et al. 2004).

This study will investigate whether a D2 agonist or a D2 antagonist can modulate the electrophysiological response to affective pictures. Decrease in dopaminergic activity will be induced by a single oral dose of $2 \mathrm{mg}$ haloperidol. This dose does not produce serious side effects (Franken et al. 2004; Kahkonen et al. 2001), and $2 \mathrm{mg}$ was shown to be able to induce modulation of the processing of neutral and rewarding information (Franken et al. 2004; Kahkonen et al. 2001). Increase in dopamine will be induced by a single oral dose of $2.5 \mathrm{mg}$ bromocriptine. Generally spoken, there are several indications that bromocriptine can modulate the response towards rewarding stimuli (Kirsch et al. 2006).

As dopamine is associated with an enhanced signalling of reward-related stimuli, it was expected that bromocriptine enhanced the processing of pleasant stimuli and haloperidol decreased the processing of pleasant stimuli. Based on the literature, the hypotheses for unpleasant stimuli could be less clearly formulated. Because some studies show that dopamine only signals stimuli associated with reward while others do find that dopamine also signals punishment-related stimuli, we expected that bromocriptine decreased the processing of unpleasant stimuli and haloperidol enhanced the processing of unpleasant stimuli. Neutral stimuli served as control conditions.

\section{Materials and methods}

Subjects and procedure

A randomized, double-blind, placebo-controlled crossover design was employed. Participants were 32 healthy right- 
handed male undergraduate psychology students and were recruited by advertisement at the university campus. All participants were non-smokers. Eleven participants could not be included in the analysis because of excessive electroencephalographic (EEG) artifacts in one of the three sessions ( $n=3$ ), drop out because of side effects (nausea) in the bromocriptine treatment $(n=6)$, or drop out because of side effects (low blood pressure, $n=1$ and nausea, $n=1$ ) in the placebo treatment. In total, 21 participants completed all three the measurement sessions, and all analyses were conducted using this sample. The mean age of the subjects was 19.8 years $(\mathrm{SD}=1.2$, range $=18-22)$.

Two weeks before the experiments, participants who were willing to participate were informed about the procedure. One week before the start of the experiments, subjects underwent a clinical psychiatric and physical examination by an experienced psychiatrist (L.P.). Eligible participants were instructed to take the medication at 8:00 A. M., 10:00 A.M., or 12:00 A.M. 4 h before each session in the laboratory. Further, they were instructed to abstain from coffee, grapefruit, alcohol, and drugs at the days of the experiment. In addition, they were instructed to abstain from alcohol and drugs the day before the experiment. The time between each session was always 1 week. All participants received a financial compensation of 50 euro. This study was approved by the Medical Ethics Committee of the Erasmus Medical Centre, Rotterdam.

\section{Treatment}

All subjects received a single oral dose of placebo (lactose), bromocriptine $(2.5 \mathrm{mg})$, and haloperidol $(2 \mathrm{mg})$ in a counterbalanced order. The medication was provided by the pharmacy of the Erasmus Medical Centre in indistinguishable capsules. It has been demonstrated that a 2-mg dose of haloperidol does not produce serious side effects in healthy subjects (Franken et al. 2004; Kahkonen et al.

Table 1 Mean (SD) valence and arousal ratings of the three sets of IAPS pictures according to the normative ratings of the IAPS database (Lang et al. 1999)

\begin{tabular}{lllll}
\hline & Set 1 & Set 2 & Set 3 & $\begin{array}{l}\text { Differences } \\
\text { between sets } \\
(F \text { values, ns) }\end{array}$ \\
\hline Neutral valence & $4.9(0.3)$ & $4.9(0.4)$ & $4.9(0.2)$ & 0.01 \\
Arousal & $2.7(0.4)$ & $2.8(0.5)$ & $2.7(0.6)$ & 0.16 \\
Pleasant valence & $7.2(0.6)$ & $7.2(0.6)$ & $7.2(0.6)$ & 0.06 \\
Arousal & $6.3(0.9)$ & $6.5(0.7)$ & $6.2(1.1)$ & 0.58 \\
Unpleasant valence & $2.5(0.6)$ & $2.6(0.5)$ & $2.6(0.7)$ & 0.05 \\
Arousal & $5.8(1.0)$ & $5.6(0.9)$ & $5.7(0.9)$ & 0.11 \\
\hline
\end{tabular}

$n s$ Not significant
2001). Further, $2.5 \mathrm{mg}$ of bromocriptine has been shown to modulate cognitive processes and in absence of side effects. Based on the literature, it was not expected that the $2.5 \mathrm{mg}$ of bromocriptine would result in serious side effects (Jarvik et al. 2000). However, after several sessions, we noticed nausea occurring in some sessions. Because we excluded all participants with nausea (with reference to the possible interaction between nausea and the viewing of affective pictures), this resulted in relatively high dropout rates. After inclusion of 15 participants, all participants in all sessions were provided with domperidone $(10 \mathrm{mg})$ to prevent nausea. Participants were instructed to take the domperidone together with the research medication ${ }^{1}$.

Stimuli and task

Before the first session, participants were instructed, and they signed informed consent. Subsequently, participants filled out the Positive and Negative Affect Scales (PANAS) questionnaire and two single-item self-rating scales that were used to assess the subjective effects of the medication (see "Questionnaires" section). After this, the participants were seated on a comfortable chair in a light and soundattenuated room. Stimuli were presented on a 21 "-monitor $1.5 \mathrm{~m}$ away from the eyes. After attaching the electrodes (approximately $15 \mathrm{~min}$ ), they were instructed to pay close attention to the pictures that would be presented. To be sure that they paid attention to the pictures, they were told that questions about the pictures would be asked after the experiment.

All pictures were taken from the International Affective Picture System (IAPS; Lang et al. 1999). To reduce testretest recognition effects, three pictures sets which were closely matched on valence and arousal ratings were used in a counterbalanced order (see Table 1). A one-way analysis of variance (ANOVA) confirmed that there were no differences in arousal and valence ratings between the three sets. Further, a repeated measures ANOVA confirmed that there were significant valence rating differences between the three affective categories, $F(2,118)=1324.2$; $p<0.001$. As expected, valence ratings for pleasant stimuli were higher than for neutral stimuli, and for neutral stimuli higher than unpleasant stimuli (higher scores indexes more pleasantness). In addition, analysis of the arousal ratings showed also significant differences between the three affective categories, $F(2,118)=304.5 ; p<0.001$. Both pleasant and unpleasant pictures had higher arousal ratings than

\footnotetext{
${ }^{1}$ We did not observe any statistical significant difference between the domperidone- and non-domperidone-receiving groups on any physiological (neutral, pleasant and unpleasant EPN and LPP) or selfreported measures (medication effects and affect).
} 
neutral pictures. In addition, pleasant stimuli had slightly higher arousal ratings as compared to the unpleasant stimuli. The neutral pictures consisted mainly of buildings, household objects, and neutral persons. The pleasant pictures consisted mainly of erotic and romantic scenes, while the unpleasant pictures consisted mainly of mutilated bodies and threat scenes.

\section{Questionnaires}

The PANAS (Watson et al. 1988) were administered as a measure of positive and negative affect. The PANAS is a 20-item bidimensional mood inventory. Positive affect reflects the extent to which a person feels enthusiastic, active, and alert (Watson et al. 1988). Negative affect is a general dimension of subjective distress and unpleasurable engagement that subsumes a variety of aversive mood states including anger, contempt, disgust, guilt, fear, and nervousness (Watson et al. 1988). Psychometric properties of the PANAS scales are good (Boon and Peeters 1999; Watson et al. 1988).

Two single-item self-rating scales were used to assess the subjective effects of the medication. A five-point Likert scale $(1=$ no effect, $5=$ a very strong effect) was used to assess the magnitude of the effect. A visual analogue scale $(0=$ very unpleasant, $100=$ very pleasant $)$ was used to assess the pleasantness of the effect.

\section{Electroencephalographic recording}

The electrophysiological signals were recorded through the Active-Two amplifier system (Biosemi, Amsterdam, The Netherlands) from 64 scalp electrodes (10-20 system) using $\mathrm{Ag} / \mathrm{AgCl}$ electrodes mounted in an elastic cap. Furthermore, six additional electrodes were attached to left and right mastoids, two outer canthi of both eyes (HEOG), infraorbital, and supraorbital regions of the eye (VEOG). Two additional scalp electrodes were used as reference and ground electrodes, respectively. Online signals were recorded from DC to $134 \mathrm{~Hz}$. All signals were digitized with a sample rate of $512 \mathrm{~Hz}$ and 24-bit A/D conversion. Data were off-line re-referenced to an average reference. Offline, EEG and EOG activity was filtered with a bandpass of 0.05-30 Hz (phase shift-free Butterworth filters; $24 \mathrm{~dB}$ / octave slope). After ocular correction (Gratton et al. 1983), epochs including an EEG signal exceeding $\pm 75 \mu \mathrm{V}$ were not included in the average. The mean 200-ms pre-stimulus period served as baseline. After baseline correction, average ERP waves were calculated for artifact-free trials at each scalp site across the three stimulus conditions and across the three treatment conditions. Brainvision Analyzer (Brain Products, München, Germany) software was used for all EEG analyses.
Data analysis

Definitions of the peaks of interest were based on previous studies using the same IAPS paradigm (Franken et al. 2007; Schupp et al. 2000, 2003a). Inspection of voltage maps of the difference waves (emotional-neutral) revealed that the EPN was maximal present at the following posterior sites: P5/6, P7/8, P9/10, PO3/4, PO7/8, and O1/2 (see Fig. 1). This site is comparable to that used by previous studies (Franken et al. 2007; Schupp et al. 2003b). To reduce the
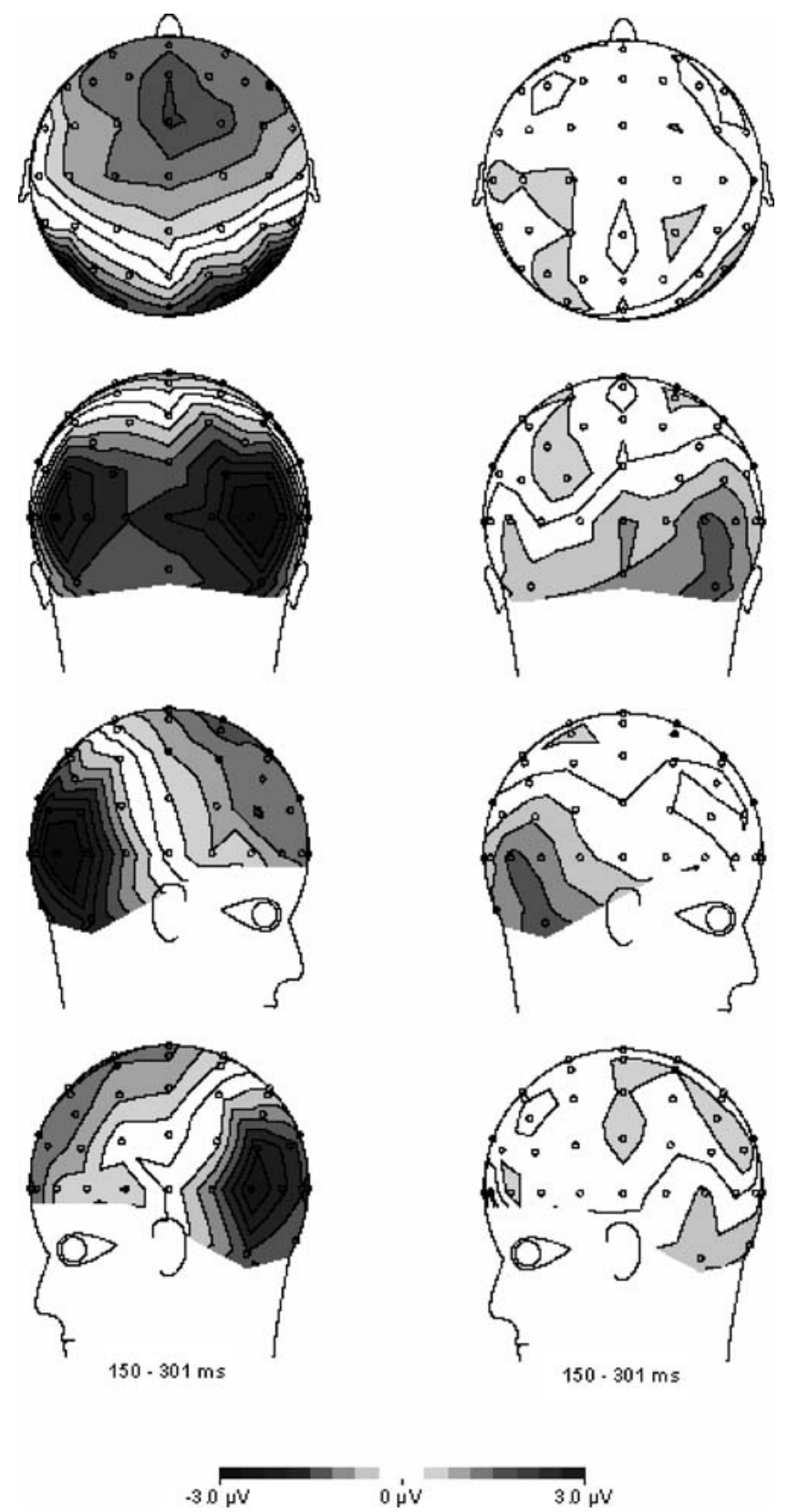

Fig. 1 Scalp topography of the EPN component (mean value in the 150- to 300-ms time window). Voltages represent difference scores: Pleasant-neutral (left panel) and unpleasant-neutral (right panel). Note that the anterior activity is positive and posterior activity is negative 
number of covarying variables and to reduce the possible influence of single spurious electrodes, these individual sites were collapsed by averaging the electrodes into one region per hemisphere (Dien and Santuzzi 2005; Schupp et al. 2003b). ${ }^{2}$ The EPN in this area was defined as the mean value of ERP activities in 150 - to $300-\mathrm{ms}$ time windows. Note that the EPN can have positive values: The EPN is a negative going potential showing reduced positivity for emotional stimuli.

Inspection of voltage maps of the difference waves (emotional-neutral) revealed that the LPP was maximal at central and centro-parietal sites C5/6, C3/4, C1/2, CP5/6, CP3/4, CP1/2, P5/6, P3/4, P1/2 (see Fig. 2). Again, these individual sites were collapsed by averaging these electrodes into one region per hemisphere. The LPP was defined as mean value of ERP response within $400-700 \mathrm{~ms}$. The LPP is a positive deflection in the EEG, and emotional stimuli increase the amplitude of this component. In addition, because in previous studies valence effects on the LPP have shown hemispheric differences (e.g., Keil et al. 2001), we exploratively included hemisphere as factor in all ANOVAs.

\section{Statistical analysis}

To test the influence of dopaminergic manipulation on the EPN and LPP components, a 3 (medication: placebo, bromocriptine, haloperidol) $\times 3$ (stimulus category: neutral, pleasant, unpleasant) $\times 2$ (hemisphere: left, right) repeated measures ANOVA was employed with all variables as within-subjects factors. For the manipulation check, a three-way repeated measures ANOVA was used for each self-reported measure (pleasantness and magnitude of medication effect, positive and negative affect). In all instances, Greenhouse-Geisser adjusted $p$ values were used. In case of a significant ANOVA result, partial Eta squared $\left(\eta^{2}\right)$ as measure of effect-size is reported. Significant ANOVA effects were followed up by pairwise comparisons with Bonferroni adjustment.

\section{Results}

\section{Self-reported effects}

There was no significant effect of treatment on the magnitude of the subjective effects of the medication, $F(2,40)=0.8 ; p=0.45$. In addition, no differences in experienced pleasantness of the medication between the conditions was observed $F(2,40)=0.0 ; p=0.96$. Further, no effects of the medication condition on negative, $F(2,40)=$ $0.8 ; p=0.45$, nor positive, $F(2,40)=0.4 ; p=0.66$, affect was

\footnotetext{
${ }^{2}$ Analysis of individual electrodes resulted in similar results.
}

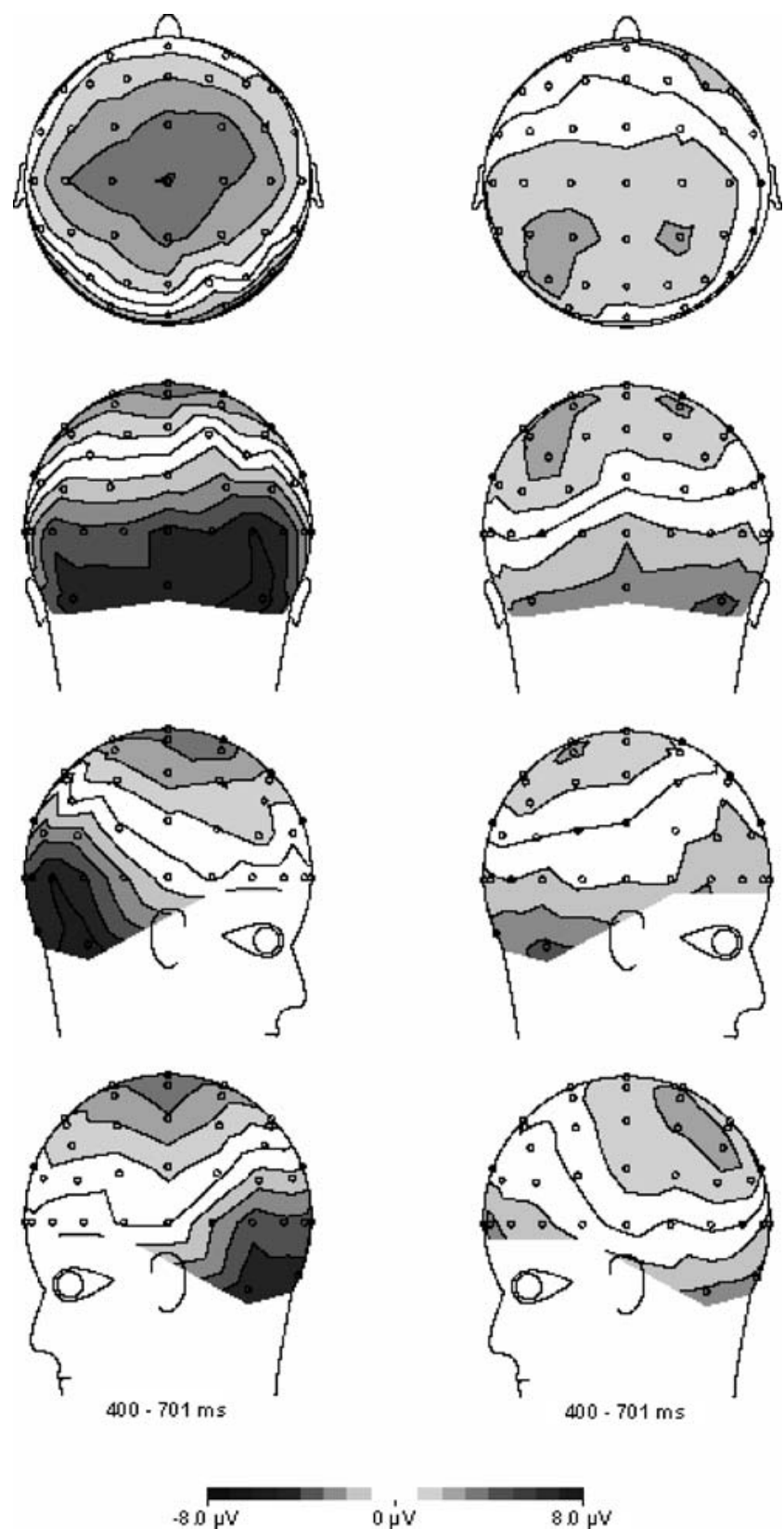

Fig. 2 Scalp topography of the LPP component (mean value in the 400- to 700-ms time window). Voltages represent difference scores: Pleasant-neutral (left panel) and unpleasant-neutral (right panel). Note that the anterior and posterior activities are negative and that the central activity is positive

observed. Summarized, no self-reported effects of medication on magnitude and pleasantness of effects and affect were observed.

\section{ERP data}

\section{EPN component}

Table 2 displays all mean values of the EPN and LPP components, including standard deviations. Figs. 3, 4, 5, 
Table 2 Mean (SD) values of the EPN and LPP components in left and right hemisphere towards neutral, pleasant, and unpleasant pictures for the placebo, bromocriptine, and haloperidol treatment conditions $(n=21)$

\begin{tabular}{llll}
\hline & Placebo & Bromocriptine & Haloperidol \\
\hline EPN neutral left & $9.4(3.6)$ & $8.4(3.7)$ & $9.4(4.4)$ \\
Right & $8.6(3.1)$ & $8.5(4.2)$ & $8.9(3.6)$ \\
EPN pleasant left & $7.0(4.3)$ & $6.0(4.0)$ & $6.9(4.2)$ \\
Right & $6.7(3.8)$ & $6.3(4.5)$ & $6.8(3.8)$ \\
EPN unpleasant left & $8.6(4.0)$ & $8.0(3.8)$ & $8.6(4.4)$ \\
Right & $8.5(4.0)$ & $8.2(4.4)$ & $8.6(4.3)$ \\
LPP neutral left & $3.5(1.6)$ & $3.2(1.9)$ & $3.4(1.8)$ \\
Right & $3.8(1.4)$ & $3.1(1.7)$ & $3.3(1.7)$ \\
LPP pleasant left & $4.9(1.9)$ & $4.6(1.8)$ & $4.8(2.1)$ \\
Right & $4.6(2.0)$ & $4.2(1.8)$ & $4.2(1.7)$ \\
LPP unpleasant left & $5.4(1.7)$ & $4.7(1.7)$ & $5.5(2.0)$ \\
Right & $4.8(1.9)$ & $4.2(1.8)$ & $4.5(1.9)$ \\
\hline
\end{tabular}

and 6 show the difference ERP waves (emotional minus neutral) for affective stimuli at the left and right hemisphere sites. As expected, a significant main effect for stimulus category was observed, $F(2,40)=81.0, p<0.001, \eta^{2}=0.80$. Pairwise follow-up analysis show that both pleasant $(p<$ $0.001)$ and unpleasant stimuli $(p<0.001)$ yielded smaller ERP values as compared to neutral stimuli, suggesting an enhanced early perceptual encoding of affective stimuli. However, no significant medication $\times$ stimulus category interaction effect was observed $F(4,80)=0.17$, ns, suggesting that dopaminergic medication had no influence on this early stage of picture processing. In addition, no other significant main or interaction effects were observed.
LPP component

Again, a significant main effect for stimulus category was observed, $F(2,40)=48.1, p<0.001, \eta^{2}=0.71$. Pairwise follow-up analysis show that both pleasant $(p<0.001)$ and unpleasant stimuli $(p<0.001)$ yielded a larger LPP component as compared to neutral stimuli, suggesting an enhanced processing for affective stimuli in the late elaborative phase. In addition, a small but significant main effect of medication was found, $F(2,40)=5.2, p<0.05, \eta^{2}=0.21$. Follow-up analysis indicated that bromocriptine resulted in overall reduced LPP waves as compared to the placebo treatment $(p<0.05)$, suggesting that bromocriptine results in an overall reduced processing of pictorial stimuli in this stage. Further, a small but significant stimulus-category $\times$ hemisphere interaction effect was observed, $F(2,40)=3.7, p<0.05, \eta^{2}=$ 0.16 . Because none of the post hoc tests resulted in a significant pairwise comparison, and this interaction had not our major interest, we will not discuss this finding in further detail. Most important for our hypothesis, no significant stimulus category $\times$ medication interaction effect was found, suggesting that the employed dopamine antagonist and agonist had no selective influence on affective processing.

\section{Discussion}

To our knowledge, this is the first study examining the influence of dopamine on ERP correlates of affective stimulus processing. The present study demonstrates that an acute low dose of bromocriptine resulted in globally
Fig. 3 Differences waves (pleasant-neutral) for pleasant stimuli at the left and right posterior cluster ( $\mathrm{P} 5 / 6, \mathrm{P} 7 / 8, \mathrm{P} 9 /$ $10, \mathrm{PO} 3 / 4, \mathrm{PO} 7 / 8$, and $\mathrm{O} 1 / 2$ ) for placebo (black line), bromocriptine (gray line), and haloperidol (dotted line) treatment conditions separately
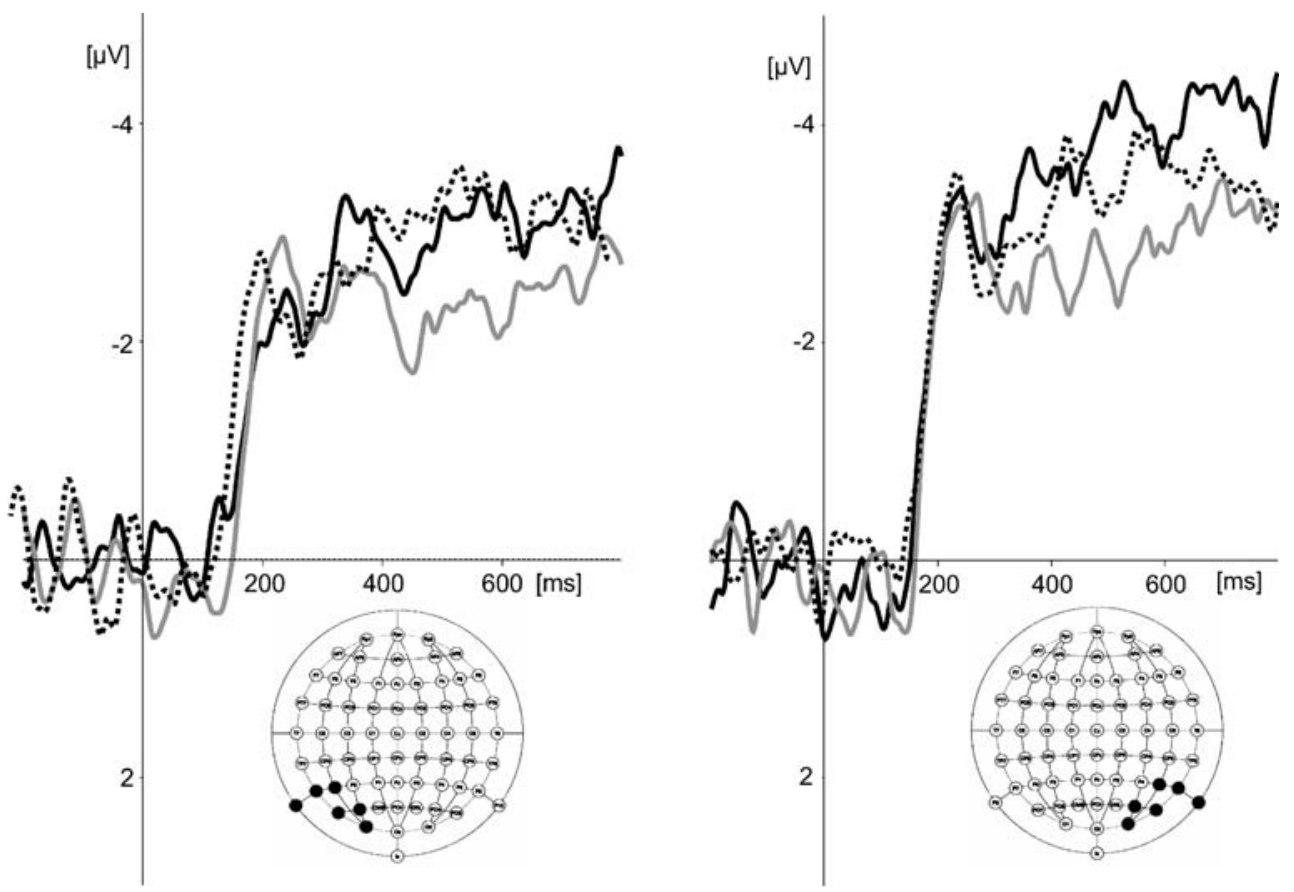
Fig. 4 Differences waves (unpleasant-neutral) for unpleasant stimuli at the left and right posterior cluster $(\mathrm{P} 5 / 6, \mathrm{P} 7)$ $8, \mathrm{P} 9 / 10, \mathrm{PO} 3 / 4, \mathrm{PO} 7 / 8$, and $\mathrm{O} 1 / 2$ ) for placebo (black line), bromocriptine (gray line), and haloperidol (dotted line) treatment conditions separately

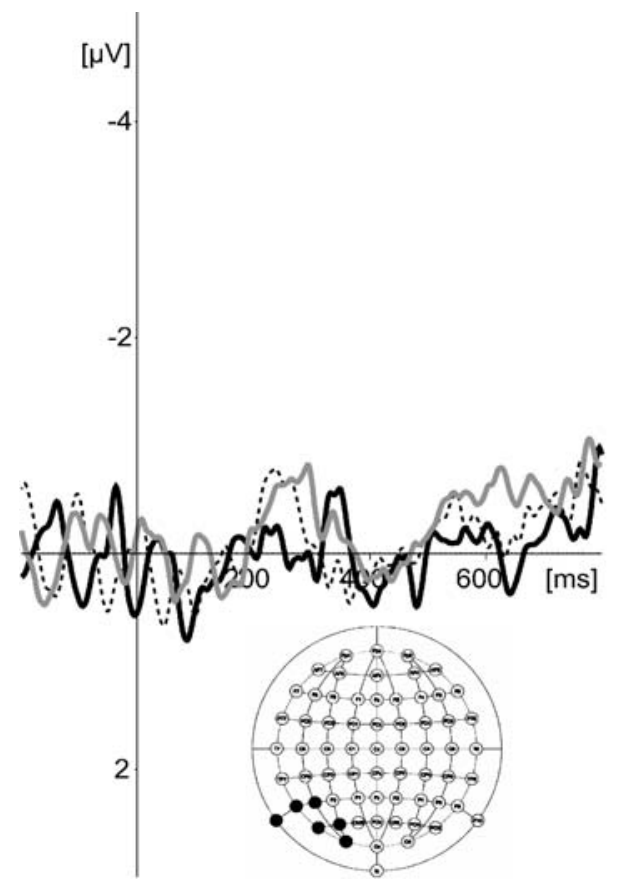

reduced LPP waves as compared to the placebo treatment, suggesting that bromocriptine results in decreased cortical processing of pictorial information. Although there are no previous studies using an acute low dose of bromocriptine examining the processing of emotional pictures (as in the present study), these results are in line with a study of Oranje et al. (2004). Although in that study a different paradigm was employed and different components were studied, these authors found a globally reduced ERP response as result of bromocriptine treatment. In contrast to bromocriptine, an acute low dose haloperidol did not result in a non-specific modification of cortical processing of pictorial information. Previous studies addressing information processing using haloperidol and ERP measures yielded mixed results. For example, Kahkonen et al. (2001) did observe a global reduction of ERP waves using $2 \mathrm{mg}$ (oral) of haloperidol. In contrast, other studies did not observe a general effect of haloperidol on ERP amplitudes
Fig. 5 Differences waves (pleasant-neutral) for pleasant stimuli at the left and right central/centro-parietal clusters (C5/6, C3/4, C1/2, CP5/6, CP3/ 4, $\mathrm{CP} 1 / 2, \mathrm{P} 5 / 6, \mathrm{P} 3 / 4, \mathrm{P} 1 / 2)$ for placebo (black line), bromocriptine (gray line), and haloperidol (dotted line) treatment conditions separately
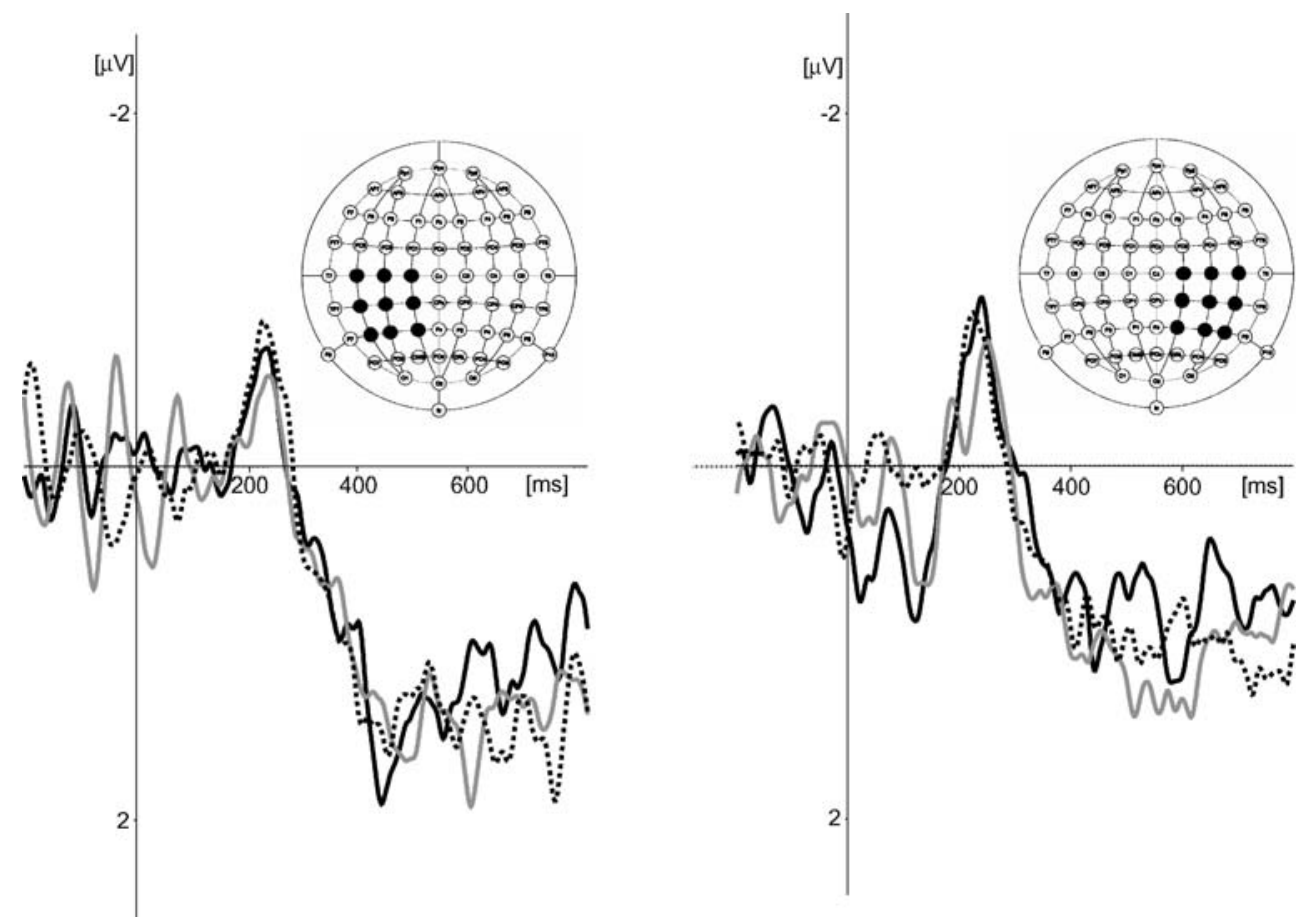
Fig. 6 Differences waves (unpleasant-neutral) for unpleasant stimuli at the left and right central clusters $(\mathrm{C} 5 / 6, \mathrm{C} 3 /$ 4, C1/2, CP5/6, CP3/4, CP1/2, $\mathrm{P} 5 / 6, \mathrm{P} 3 / 4, \mathrm{P} 1 / 2)$ for placebo (black line), bromocriptine (gray line), and haloperidol (dotted line) treatment conditions separately

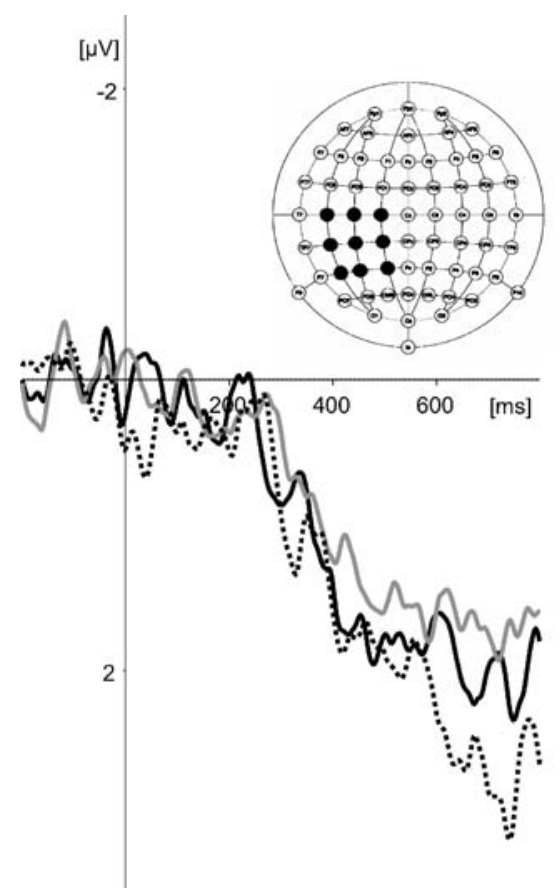

(e.g. Ford et al. 1994). Clearly, the effects of haloperidol on ERPs are dependent on dose, ERP component, characteristics of the participants, and experimental paradigms that are used.

Most importantly, we could not confirm the hypothesis that $\mathrm{D} 2$ receptor modulation results in a modulation of cortical processing of affective stimuli. Neither an acute low dose of bromocriptine nor an acute low dose of haloperidol did differentially modulate the brain's electrophysiological response towards affective stimuli. This finding suggests that dopamine D2 receptors are not involved in the cortical processing of affective information. Because the studied ERP components measured in the present study are associated with attentive motivational processing (Schupp et al. 2006, 2007), it can be concluded that motivational attentive processing is not affected by haloperidol nor bromocriptine. Given that the ERPs in the present study reflect attentive processing, the results are in line with Oranje et al. (2006) who did not find any effects of L-dopa nor bromocriptine on ERP indices of selective attention in healthy volunteers.

In addition to the main finding that modulation of the D2 receptor did not result in early (EPN) or late (LPP) effect on ERPs indexing early perceptual encoding of emotional material and subsequent elaborative processing, we did not observe an effect of haloperidol and bromocriptine on the subjective self-reported affect. Neither medication had an effect on positive or negative affect. However, it must be noted that the present study was not specifically designed to measure the subjective effects of the medication. In addition, although the present results show that dopamine is not associated with the perception of reward-associated stimuli per se, it still might be associated with establishing stimulus-reward associations or functions dealing with reward-related motor responses. In addition, it might be that the reward processing is only modulated by dopaminergic agents in persons with a genetically heightened reward sensitivity, for example, carriers of the A1 allele of the dopamine D2 TaqIA gene (Kirsch et al. 2006).

The present study suggests that low doses of bromocriptine in Parkinson's disease patients and haloperidol in schizophrenia patients may have limited influence on affective processing and self-reported affect in patients having these disorders. However, it must be noted that we did only study the effects of an acute dose of these medications; it is not known whether these effects differ from those associated with long term use of medication.

The present study has several limitations. First, there was a substantial dropout in the bromocriptine treatment. It may be that this is a specific subgroup of persons with heightened sensitivity for dopamine agonists. Because this group is not included in the analysis, this might have resulted in lowered generalizability of the results. Second, because of risks of unwanted side effects, we employed rather low doses of bromocriptine and haloperidol, $2 \mathrm{mg}$ and $2.5 \mathrm{mg}$, respectively. Third, a possible limitation of this study is that some participants received domperidone and others did not, which may have influenced the results. However, it must be noted that domperidone does not cross the blood-brain barrier but exerts its effect peripherally, and as such, does not have a major influence on the central dopamine system (Barone 
1999; Champion et al. 1986). In addition, additional statistical analyses show that domperidone did not influence any of the outcome variables (electrophysiological nor selfreported) used in the present study.

Summarizing, the present results indicate that neither an acute low dose of bromocriptine nor an acute low dose of haloperidol has selective effect on electrophysiological indices of affective processing and self-reported affect. In contrast, bromocriptine decreased overall processing of all stimulus categories regardless of their affective content. The results indicate that dopaminergic D2 receptors do not seem to play a crucial role in the selective processing of affective visual stimuli.

\section{References}

Ashby FG, Isen AM, Turken U (1999) A neuropsychological theory of positive affect and its influence on cognition. Psychol Rev 106:529-550

Barone JA (1999) Domperidone: a peripherally acting dopamine2receptor antagonist. Ann Pharmacother 33:429-440

Boon MT, Peeters FP (1999) Affectieve dimensies bij depressie en angst [Dimensions of affectivity in depression and anxiety]. Tijdschrift voor Psychiatrie 41:109-113

Burgdorf J, Panksepp J (2006) The neurobiology of positive emotions. Neurosci Biobehav Rev 30:173-187

Cacioppo JT, Crites SL, Gardner WL, Bernston GG (1994) Bioelectrical echoes from evaluative categorizations: I. A late positive brain potential that varies as a function of trait negativity and extremity. J Pers Soc Psychol 67:115-125

Champion MC, Hartnett M, Yen M (1986) Domperidone, a new dopamine antagonist. Can Med Assoc J 135:457-461

Codispoti M, Ferrari V, Bradley MM (2007) Repetition and eventrelated potentials: Distinguishing early and late processes in affective picture perception. J Cogn Neurosci 19:577-586

Cuthbert BN, Schupp HT, Bradley MM, Birbaumer N, Lang PJ (2000) Brain potentials in affective picture processing: covariation with autonomic arousal and affective report. Biologic Psychol 52:95111

Day JJ, Carelli RM (2007) The nucleus accumbens and Pavlovian reward learning. Neuroscientist 13:148-159

Dien J, Santuzzi AM (2005) Application of repeated measures ANOVA to high-density ERP data-sets: a review and tutorial. In: Handy TC (ed) Event-related potentials: a methods handbook. The MIT Press, Cambridge, pp 57-82

Ford JM, White PM, Csernansky JG, Faustman WO, Roth WT, Pfefferbaum A (1994) ERPs in schizophrenia: effects of antipsychotic medication. Biol Psychiatry 36:153-170

Franken IHA (2003) Drug craving and addiction: integrating psychological and neuropsychopharmacological approaches. Prog Neuropsychopharmacol Biol Psychiatry 27:563-579

Franken IHA, Hendriks VM, Stam CJ, van den Brink W (2004) A role for dopamine in the processing of drug cues in heroin dependent patients. Eur Neuropsychopharmacol 14:503-508

Franken IHA, Nijs IMT, Muris P, Van Strien JW (2007) Alcohol selectively reduces brain activity during the affective processing of negative information. Alcoholism: Clinical and Experimental Research 31:919-927
Gratton G, Coles MGH, Donchin E (1983) A new method for off-line removal of ocular artifact. Electroencephalogr Clin Neurophysiol $55: 468-484$

Jarvik ME, Caskey NH, Wirshing WC, Madsen DC, Iwamoto-Schaap PN, Elins JL, Eisenberger NI, Olmstead RE (2000) Bromocriptine reduces cigarette smoking. Addiction 95:1173-1183

Kahkonen S, Ahveninen J, Jaaskelainen IP, Kaakkola S, Naatanen R, Huttunen J, Pekkonen E (2001) Effects of haloperidol on selective attention: a combined whole-head MEG and high-resolution EEG study. Neuropsychopharmacology 25:498-504

Kapur S (2003) Psychosis as a state of aberrant salience: a framework linking biology, phenomenology, and pharmacology in schizophrenia. Am J Psychiatry 160:13-23

Keil A, Muller MM, Gruber T, Wienbruch C, Stolarova M, Elbert T (2001) Effects of emotional arousal in the cerebral hemispheres: a study of oscillatory brain activity and event-related potentials. Clin Neurophysiol 112:2057-2068

Keil A, Bradley MM, Hauk O, Rockstroh B, Elbert T, Lang PJ (2002) Large-scale neural correlates of affective picture processing. Psychophysiology 39:641-649

Kemp AH, Gray MA, Silberstein RB, Armstrong SM, Nathan PJ (2004) Augmentation of serotonin enhances pleasant and suppresses unpleasant cortical electrophysiological responses to visual emotional stimuli in humans. NeuroImage 22:1084 1096

Kirsch P, Reuter M, Mier D, Lonsdorf T, Stark R, Gallhofer B, Vaitl D, Hennig J (2006) Imaging gene-substance interactions: The effect of the DRD2 TaqIA polymorphism and the dopamine agonist bromocriptine on the brain activation during the anticipation of reward. Neurosci Lett 405:196-201

Lang PJ, Bradley MM, Cuthbert BN (1999) International affective picture system (IAPS): instruction manual and affective ratings. The Center for Research in Psychophysiology, University of Florida, Gainsville, FL

Mitul AM, Rachel S, Alan DO, Barbara S, Trevor WR (2001) Improved short-term spatial memory but impaired reversal learning following the dopamine D2 agonist bromocriptine in human volunteers. Psychopharmacology 159:10-20

Mizrahi R, Rusjan P, Agid O, Graff A, Mamo DC, Zipursky RB, Kapur S (2007) Adverse subjective experience with antipsychotics and its relationship to striatal and extrastriatal D2 receptors: a PET study in schizophrenia. Am J Psychiatry 164:630-637

Oranje B, Gispen-de Wied CC, Westenberg HG, Kemner C, Verbaten MN, Kahn RS (2004) Increasing dopaminergic activity: effects of L-dopa and bromocriptine on human sensory gating. J Psychopharmacol 18:388-394

Oranje B, Gispen-de Wied CC, Westenberg HG, Kemner C, Verbaten MN, Kahn RS (2006) No effects of 1-dopa and bromocriptine on psychophysiological parameters of human selective attention. J Psychopharmacol 20:789-798

Robbins TW, Everitt BJ (2007) A role for mesencephalic dopamine in activation: commentary on Berridge (2006). Psychopharmacology 191:433-437

Robinson TE, Berridge KC (1993) The neural basis of drug craving: an incentive-sensitization theory of addiction. Brain Res Rev $18: 247-291$

Rule RR, Shimamura AP, Knight RT (2002) Orbitofrontal cortex and dynamic filtering of emotional stimuli. Cogn Affect Behav Neurosci 2:264-270

Saeedi H, Remington G, Christensen BK (2006) Impact of haloperidol, a dopamine D2 antagonist, on cognition and mood. Schizophr Res 85:222-231

Schultz W (1997) Dopamine neurons and their role in reward mechanisms. Curr Opin Neurobiol 7:191-197 
Schupp HT, Cuthbert BN, Bradley MM, Cacioppo JT, Ito T, Lang PJ (2000) Affective picture processing: The late positive potential is modulated by motivational relevance. Psychophysiology 37:257261

Schupp HT, Junghoefer M, Weike AI, Hamm AO (2003a) Attention and emotion: an ERP analysis of facilitated emotional stimulus processing. Neuroreport 14:1107-1110

Schupp HT, Junghoefer M, Weike AI, Hamm AO (2003b) Emotional facilitation of sensory processing in the visual cortex. Psychol Sci 14:7-13

Schupp HT, Flaisch T, Stockburger J, Junghofer M (2006) Emotion and attention: event-related brain potential studies. Prog Brain Res 156:31-51

Schupp HT, Stockburger J, Codispoti M, Junghofer M, Weike AI, Hamm AO (2007) Selective visual attention to emotion. J Neurosci 27:1082-1089

Takahashi H, Yahata N, Koeda M, Takano A, Asai K, Suhara T, Okubo Y (2005) Effects of dopaminergic and serotonergic manipulation on emotional processing: a pharmacological fMRI study. NeuroImage 27:991-1001
Taylor SF, Luan Phan K, Britton JC, Liberzon I (2005) Neural response to emotional salience in schizophrenia. Neuropsychopharmacology 30:984-995

Tessitore A, Hariri AR, Fera F, Smith WG, Chase TN, Hyde TM, Weinberger DR, Mattay VS (2002) Dopamine modulates the response of the human amygdala: a study in Parkinson's disease. J Neurosci 22:9099-9103

Vuilleumier P (2005) How brains beware: neural mechanisms of emotional attention. Trends Cogn Sci 9:585-594

Watson D, Clark LA, Tellegen A (1988) Development and validation of brief measures of positive and negative affect: The PANAS Scales. J Pers Soc Psychol 54:1063-1070

Wieser MJ, Muhlberger A, Alpers GW, Macht M, Ellgring H, Pauli P (2006) Emotion processing in Parkinson's disease: dissociation between early neuronal processing and explicit ratings. Clin Neurophysiol 117:94-102

Willner P, Hale AS, Argyropoulos S (2005) Dopaminergic mechanism of antidepressant action in depressed patients. J Affect Dis 86:37-45

Wise RA, Bozarth MA (1985) Brain mechanisms of drug reward and euphoria. Psychiatry Med 3:445-460 